\title{
Individual and organizational factors related to social vitality of women working in Birjand University of Medical Sciences, Iran, in 2020
}

\author{
Maryam Bahlgerdi ${ }^{1}$, Mohammadreza Miri ${ }^{i}{ }^{2}$, Enseiye Norozi $^{\left({ }^{3}\right.}$, \\ Gholamreza Sharifzadeh
}

\begin{abstract}
Background and Aims: Happiness and vitality are among the most important and effective components in the process of human life, without which activity, creativity, initiative, invention, and healthy life cannot be created. Happiness is a valuable tool for improving the personality and job performance of employees; meaning that happy people are more successful in the workplace. The creation of social vitality is the priority for comprehensive intervention in South Khorasan Province, Iran, for comprehensive intervention. Therefore, this study aimed to investigate the individual and organizational factors related to the social vitality of women working at the Birjand University of Medical Sciences, Birjand, Iran.
\end{abstract}

Materials and Methods: This descriptive-analytical cross-sectional study was performed on 214 females working at Birjand University of Medical Sciences selected using a systematic random sampling method in 2019. The 29-item Oxford Happiness Standard was used to collect data to measure social vitality.

Results: The mean score of the females' happiness was estimated at $73.55 \pm 12.32$ and the majority of the subjects had moderate happiness (60.3\%). Moreover, most of the cases had not participated in happiness courses before $(85.6 \%)$. The results also showed that happiness had no significant relationship with age, educational level, marital status, education level of the spouse, and occupation of spouse among the women $(\mathrm{P}>0.05)$; however, happiness showed a significant relationship with income and place of residence $(\mathrm{P}<0.05)$.

Conclusion: It seems that the social vitality of working women was moderate; in this respect, it is recommended to officials and planners implement educational interventions to improve the vitality of employees.

Keywords: Individual and organizational factors, Social vitality, Working women

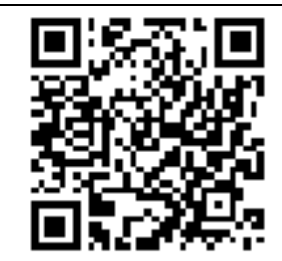

Citation: Bahlgerdi M, Miri MR, Norozi E, Sharifzadeh Gh. [Individual and organizational factors related to social vitality of women working in Birjand University of Medical Sciences, Iran, in 2020]. J Birjand Univ Med Sci. 2021; 28(2): 170-178. [Persian]

DOI http://doi.org/10.32592/JBirjandUnivMedSci.2021.28.2.107

Received: March 17, $2020 \quad$ Accepted: June 2, 2020

\footnotetext{
${ }^{1}$ Student Research Committee, Department of Health Education and Health Promotion, School of Health, Birjand University of Medical Sciences, Birjand, Iran

${ }^{2}$ Social Determinants of Health Research Center, Department of Health Education and Health Promotion, School of Health, Birjand university of medical sciences, Birjand, Iran

3 Social Determinants of Health Research Center, Department of Epidemiology and Biostatistics, School of Health, Birjand university of medical sciences, Birjand, Iran
}

Corresponding author: Social Determinants of Health Research Center, Department of Health Education and Health Promotion, School of Health, Birjand university of medical sciences, Birjand, Iran

Tel: +985632381654 Fax:05631631651 E-mail: Miri_moh2516@yahoo.com 


\section{بررسى عوامل فردى و سازمانى مرتبط با نشاط اجتماعى زنان شاغل در دانشكاه علوم يزشكى بير جند

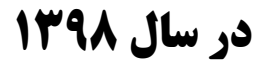

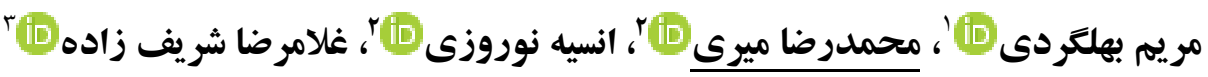

\section{جـ}

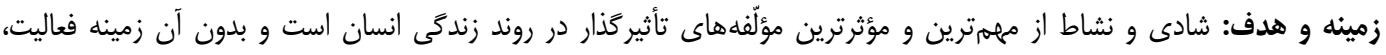

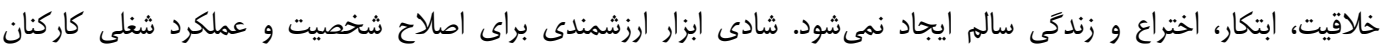

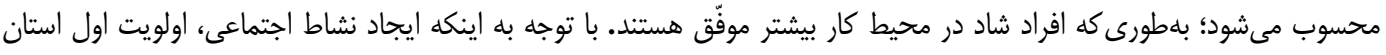

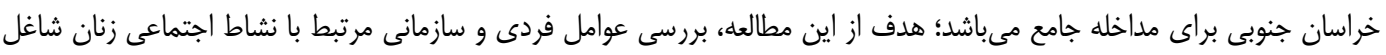

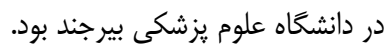

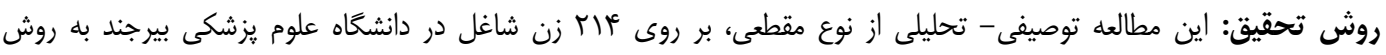

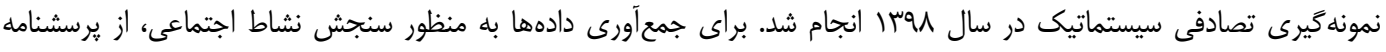
استاندارد وجاسؤالى شادكامى آكسفورد استفاده كرديد

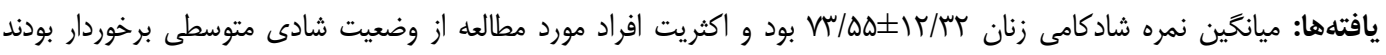

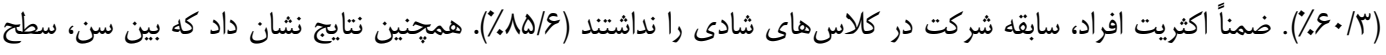

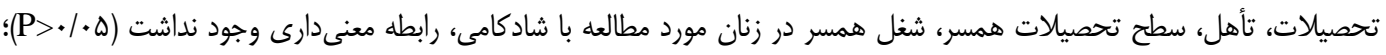

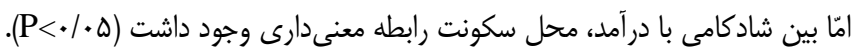

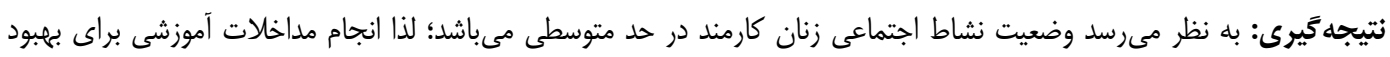

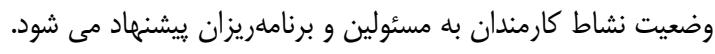
وازههاى كليدى: عوامل فردى و سازمانى، نشاط اجتماعى، زنان شاغل

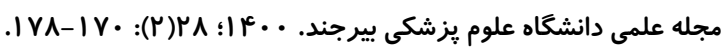
دريافت:

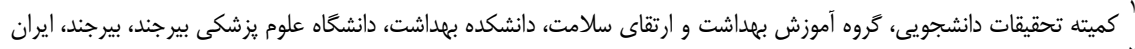

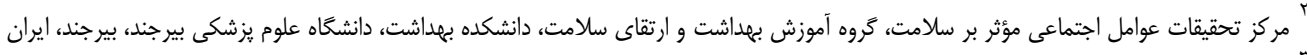

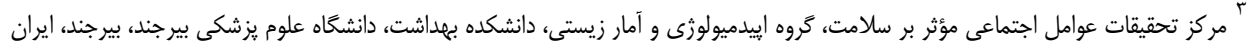

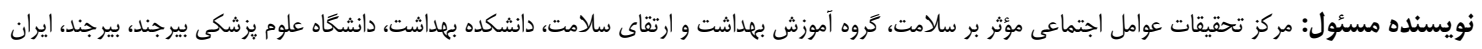

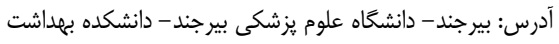

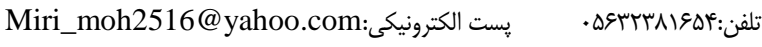


رتبه ه+ا ام قرار دارد. بر ايناساس جامعه ايران بين كشورهاى با

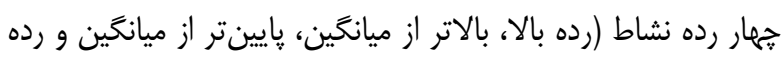

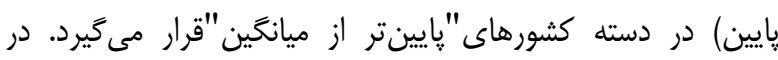

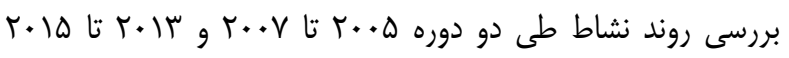

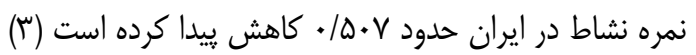

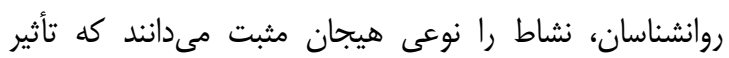

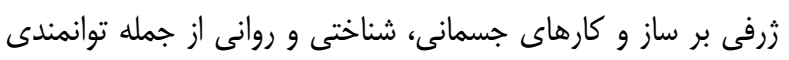

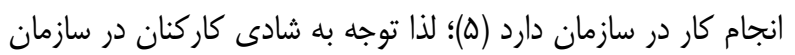
و فراهم كردن زمينه شادى آنها راهى مؤثر و قابل اعتماد براى داى دان دان سان سان

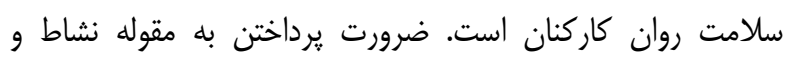

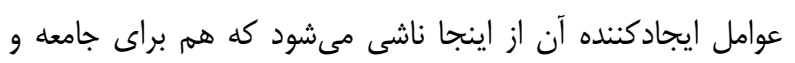

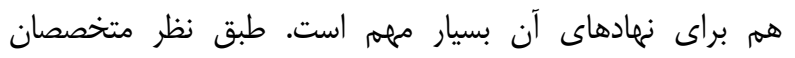
مديريت، بزركترين كليد براى بهرهورى، داشتن كاركنان شاد است. بين شادى در كار و بجرهورى ارتباط روشنى وجود دارد. از ديخر آثار شادى و نشاط در محيط كار مىتوان به افزايش سود، افزايش توليد،

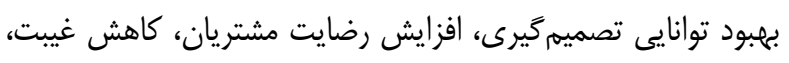

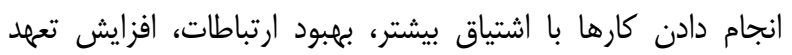

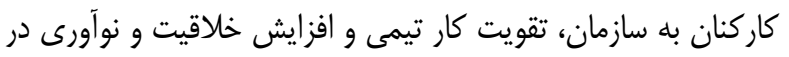

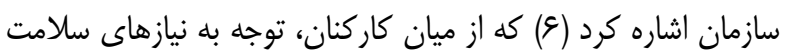
روانى زنان از اهميت خاصى برخوردار است كه در اين ميان زنان

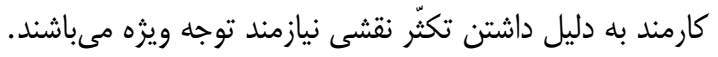

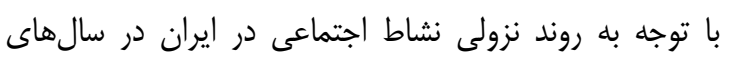

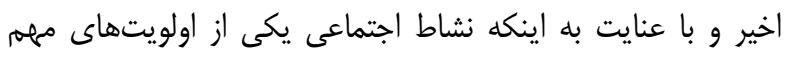
نظام سلامت محسوب مى شود و از طرفى نقش خطير زنان كارمند،

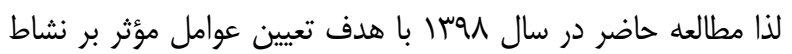
اجتماعى در زنان كارمند دانشگاه علوم يزشكى بيرجند انجام گرفت.

\section{روش تحقيق}

مطالعه حاضر از نوع توصيفى تحليلى بود كه بلهورت مقطعى،

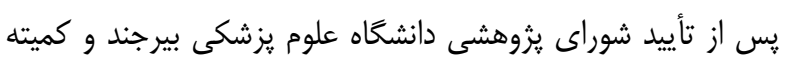

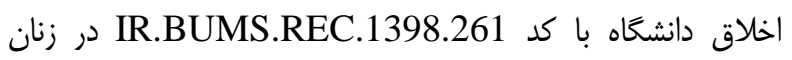
شاغل در ستاد دانشعاه انجام شد. مقلdمه

يكى از موضوعات و نيازهاى مهم هر جامعه براى قشرهاى

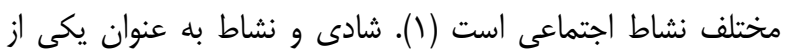

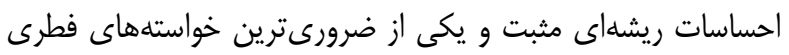

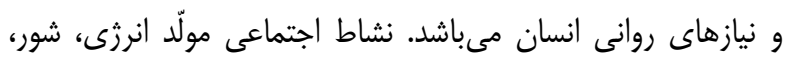

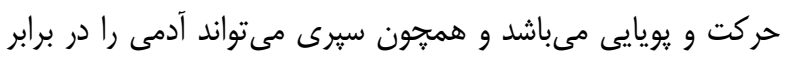

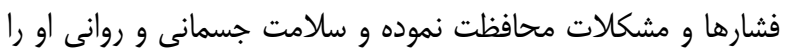
نيز تضمين كند (T). نشاط اجتماعى نقش تعيين كننداه در در تأمين

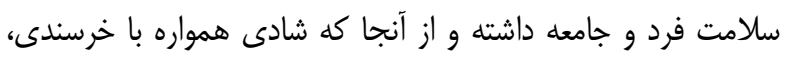
خوشبينى، اميد و اعتماد همراه است، مىتواند نقش تسريع كنندهاى

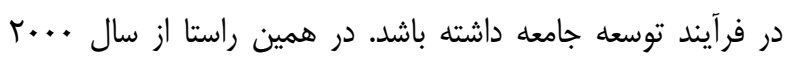

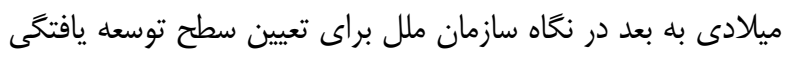

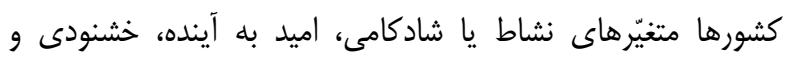
رضايتمندى افراد جامعه نيز به عنوان يكى متغيّر كليدى وارد نئه

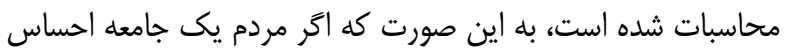

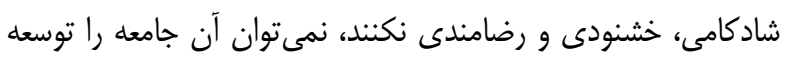

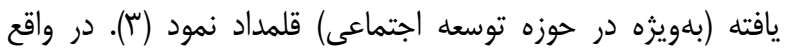

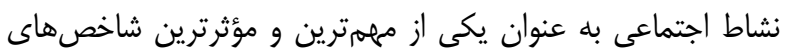

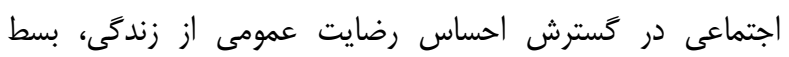

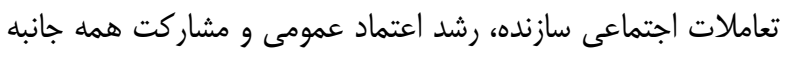
اجتماعى به شمار مى رود (ए). علىرغم اهميت بحث نشاط اجتماعى، مطالعات كلى در ايران و جهان حاكى از اين است كه وضعيت كلى نشاط در جامعه ايران مناسب نيست(أ, ب)؛ به عنوان مثال نتايج مطالعهاى نشان دان داد كه

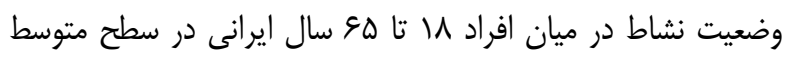

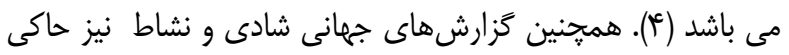

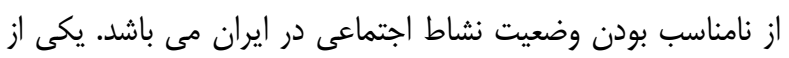

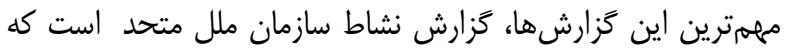

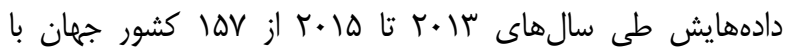

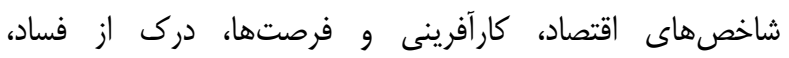
بخشندكى، سلامت، اطمينان، امنيت و آزادى هاى فردى جمعآ آورى

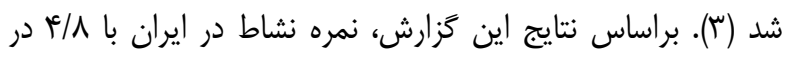


(سال)، وضعيت خدمت (مدير واحد، كارشناس مسئول واحد، كارشناس واحد) استفاده گرديد.

نمره شادكامى به سه سطح ضعيف (نمره كمتر از هA)، متوسط

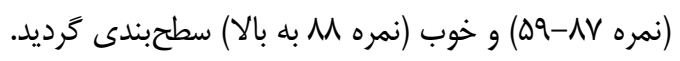

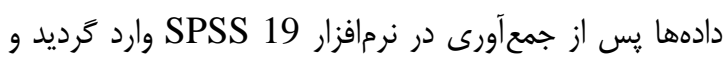

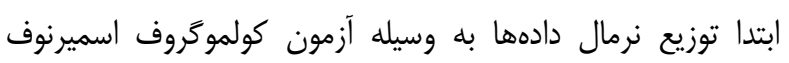

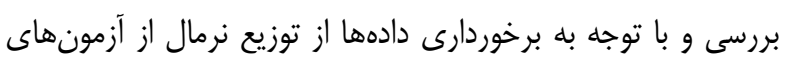

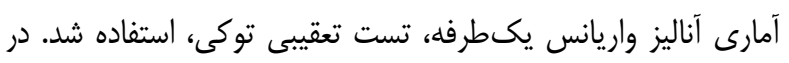

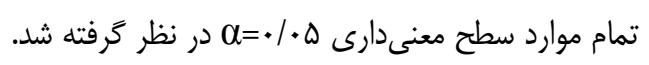

\section{يافته ها}

در اين مطالعه عآ ز زن شاغل در واحدهاى ستادى دانشعاه علوم يزشكى بيرجند مورد مطالعه قرار كرفتند. ميانكين سنى افراد

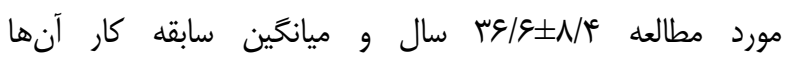

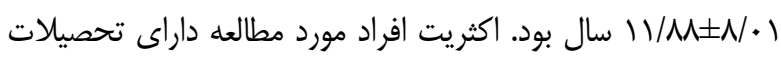

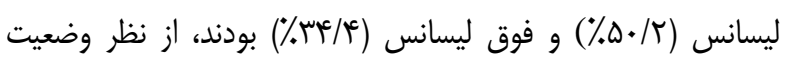

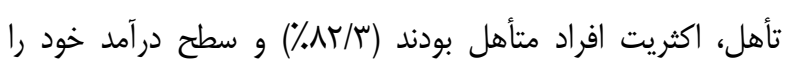

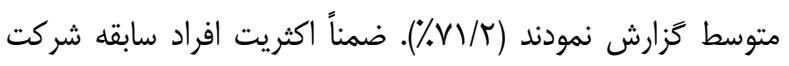

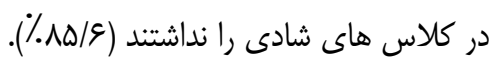
ميانكين نمره شادكامى زنان

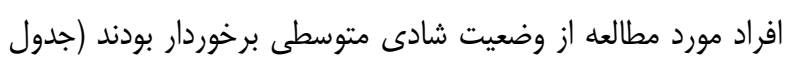

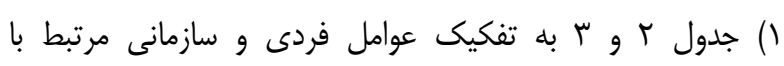
شادكامى را نشان مى دهد. نتايج نشان داد كه مقايسه ميانخين نمره شادكامى بر حسب سن، سطح تحصيلات، تأهل، سطح تحصيلات

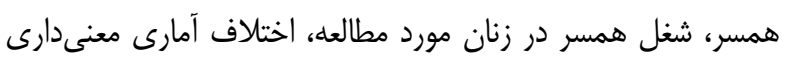

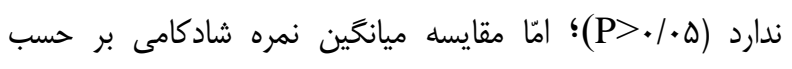

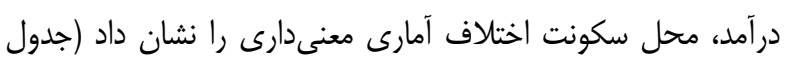

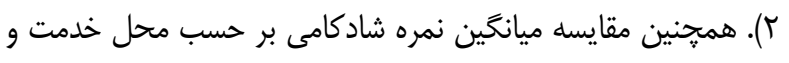
وضعيت خدمت اختلاف آمارى معنى دارى را نشان نداد (جدول ساب).
حجم نمونه بر اساس مطالعه معينى و همكاران (V) و براساس

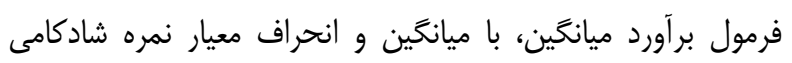

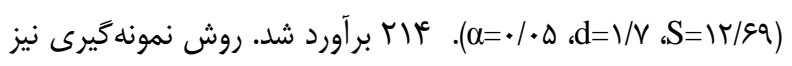
بلهصورت تصادفى سيستماتيك بود. به اين صورت كه ابتدا ليست

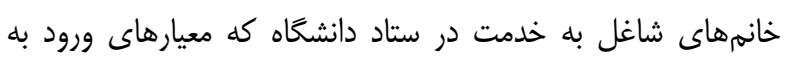

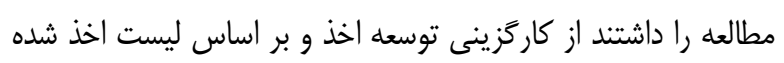
فاصله نمونهَيرى از تقسيم تعداد كل افراد مورد مطالعه بر تعداد

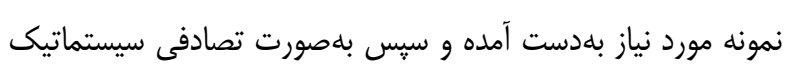
اقدام به انتخاب نمونه ترديد. معيارهاى ورود مطالعه شامل شاغل بودن در ستاد دانشخاه، حداقل سابقه يك سال خدمت، عدم مصرف داروهاى اعصاب و

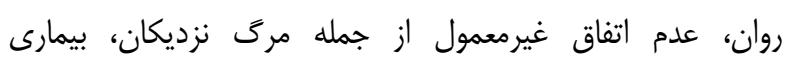

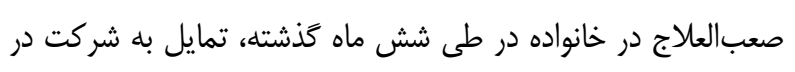
مطالعه بود. معيار خروج تكميل ناقص يرسشنامهها بود.

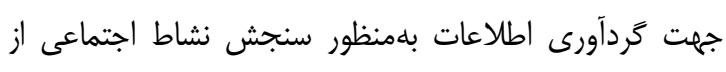

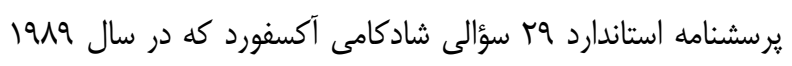
توسط 'Argyle\&lo تهيه شده است، استفاده گرديد. نمرهذارى يرسشنامه در يك طيف جهار گزينهاى از يكى تا جهار انجام شد.

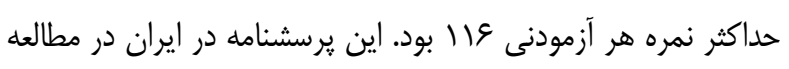

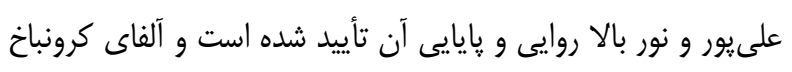

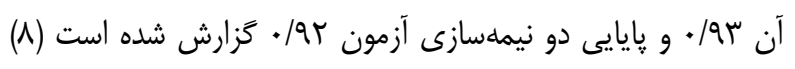

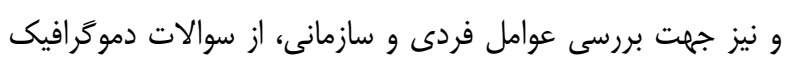
محققساخته شامل: سن، سطح تحصيلات (دييلم- فوق دييلمليسانس- فوق ليسانس- دكترى)، محل خدمت سناته (حوزه رياست،

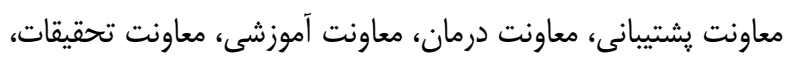

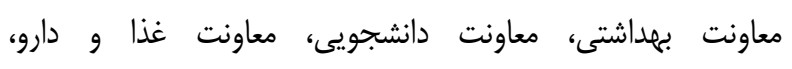
دانشكدهها)، وضعيت تأهل (مجرد- متاهل - بيوه- مطلقه)، تعداد فرزندان، تحصيلات همسر (بيسواد، ابتدايى، راهنمايى، متوسطه، وانهاه دانشگاهى)، شغل همسر، درآمد خانواده (ضعيف- متوسط - خوب) وضعيت محل سكونت (شخصى-اجاره يا رهن- سازمانى - منزل والدين)، سابقه شركت در كلاسهاى شادى و شادكامى، سابقه كار

\footnotetext{
${ }^{1}$ Argyle\&lo
} 
جدول ا - توزيع فراوانى نمره شادكامى در زنان مورد مطالعه

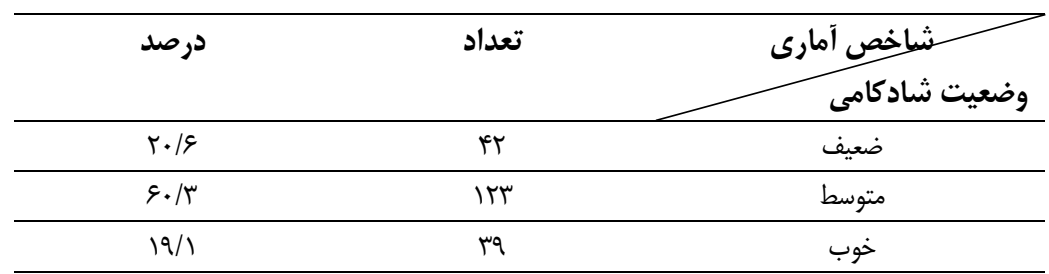

جدول ؟ - مقايسه ميانكين نمره شادكامى به تفكيك عوامل فردى در زنان مورد مطالعه

\begin{tabular}{|c|c|c|c|c|}
\hline $\begin{array}{l}\text { نتيجه آزمون آمارى } \\
\text { ANOVA }\end{array}$ & $\mathrm{X} \pm \mathrm{SD}$ & فراوانى & شاخص آمارى & نام متغير \\
\hline \multirow[t]{3}{*}{$\mathrm{P}=\cdot / 109$} & $V D / V \pm I T / K G$ & $F \cdot(1 N / 9)$ & كمتر از هT سال & سن \\
\hline & $V \Psi / q r \pm|r / \mu|$ & $\operatorname{s\varphi }(T Q / \Lambda)$ & מال & \\
\hline & $V \Psi / I I \pm I r / \mu V$ & $\Delta f(T \Delta / I)$ & re r سال به بالا & \\
\hline \multirow[t]{5}{*}{$\mathrm{P}=\cdot / 4 q$} & $V r / V \pm I r / V$ & $9(f / T)$ & دييلم & سطح تحصيلات \\
\hline & $s V / q \pm 1 r / \Lambda$ & $1 \%(\varnothing)$ & فوق دييلم & \\
\hline & $V r / \Lambda \pm I r / r^{c}$ & $1 \cdot 1(\Delta \cdot / r)$ & ليسانس & \\
\hline & $V r / \Lambda \pm I 1 / \Lambda$ & $V F(M F / F)$ & فوق ليسانس & \\
\hline & $v \varepsilon / \Delta \pm 1 r / q$ & $\|(\Delta / 1)$ & دكترا & \\
\hline \multirow[t]{3}{*}{$\mathrm{P}=\cdot / \mu r$} & $V \backslash / \Delta \pm 1 \cdot / 8$ & rr (IF/q) & مجرد & تاهل \\
\hline & $V \Psi / \Lambda \pm I r / \Delta$ & $\operatorname{IVV}(\Lambda r / T)$ & متاهل & \\
\hline & $S N / Y \pm I T / F$ & $q(T / \Lambda)$ & بيوه و مطلقه & \\
\hline تست توكى & $\varepsilon r / r \pm V / q$ & $\|(\xi)$ & ضعيف & درآمد \\
\hline متوسط با ضعيف & $V r / V \pm I I / \Delta$ & $\operatorname{lQT}(\mathrm{V} / \mathrm{T})$ & متوسط & \\
\hline $\mathrm{P}=\cdot / \cdot . \wedge$ & $V N / A \pm I T / r$ & rq (Tr/A) & خوب & \\
\hline \multicolumn{5}{|l|}{ خوب با ضعيف } \\
\hline \multicolumn{5}{|l|}{$\mathrm{P}=\cdot / \cdot \cdot 1$} \\
\hline \multicolumn{5}{|l|}{ خوب بامتوسط } \\
\hline \multicolumn{5}{|l|}{$\mathrm{P}=\cdot / \cdot \bullet$} \\
\hline تست توكى & $V \varphi / \Delta \pm I T / 1$ & $1 \% \cdot(\varepsilon \cdot / \Delta)$ & شخصى & محل سكونت \\
\hline شخصى با منزل والدين & $V \pi / \varepsilon \pm I r / \Lambda$ & $\Delta Q(T V / F)$ & اجاره & \\
\hline \multirow[t]{2}{*}{$\mathrm{P}=. / . \leftarrow$} & 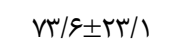 & $\Delta(T / r)$ & سازمانى & \\
\hline & $s V / r \pm V / S$ & rI (৭/A) & منزل والدين & \\
\hline \multirow[t]{2}{*}{ ANOVA } & $V \cdot / \mu \Psi \pm \mid \varepsilon / \mu \varphi$ & $r(1 / \mathscr{c})$ & بى سواد & سطح تحصيلات همسر \\
\hline & & $\Gamma(1 / \tilde{\Psi})$ & ابتدايى & \\
\hline \multirow[t]{3}{*}{$\mathrm{P}=\cdot / 1$} & $\Lambda T / \Lambda \pm I \cdot / \Delta S$ & $\Delta(r / r)$ & راهنمايى & \\
\hline & $9 q / .9 \pm 11 / r r$ & $r(1 \cdot / r)$ & متوسطه & \\
\hline & $V \varphi / \varepsilon \Delta \pm \mid r / \mu r$ & ITV (qא/V) & دانشكاهى & \\
\hline \multirow[t]{4}{*}{$\mathrm{P}=\cdot / \Delta \varphi$} & $v \varepsilon / \Lambda r \pm I r / \Delta$ & $\| r(\Delta r / I)$ & كارمند & شغل همسر \\
\hline & $V \backslash / q \pm 11 / \propto q$ & $1 \cdot(r / v)$ & بازنشسته & \\
\hline & $V r / 9 q \pm 1) / M$ & एव(INI) & آزاد & \\
\hline & $\Lambda T \pm \| f / \Lambda F$ & $r(9)$ & ساير س & \\
\hline
\end{tabular}


جدول سـ- مقايسه ميانكَين نمره شادكامى به تفكيك عوامل سازمانى در زنان مورد مطالعه

\begin{tabular}{|c|c|c|c|}
\hline $\begin{array}{l}\text { نتيجه آزمون آمارى } \\
\text { ANOVA }\end{array}$ & $\mathrm{X} \pm \mathrm{SD}$ & فر اوانى (درصد) & نام متغير آمارى \\
\hline \multirow[t]{10}{*}{$\mathrm{P}=\cdot / 1$} & & & محل خدمت \\
\hline & $9 \vee / q \pm N / q$ & $M(\Lambda / c)$ & رياست \\
\hline & $V r / q \pm 11 / 1 Q$ & $r \Delta(11 / s)$ & معاونت شֶتيبانى \\
\hline & $V N / \uparrow \pm 11 / q$ & $1 \%(\varepsilon)$ & معاونت درمان \\
\hline & $v \pi / \Lambda \pm 1 r / q$ & $1 \cdot(r / V)$ & معاونت آموزشى \\
\hline & $V / q \pm 14 / q$ & $M(N / \mathcal{F})$ & معاونت تحقيقات \\
\hline & $V M / \perp \pm I r / r$ & एq(IN/I) & معاونت بهداشتى \\
\hline & $v / / \pm 11 / \Delta$ & $M(\Lambda / \mathcal{F})$ & معاونت دانشجويى \\
\hline & $V \varepsilon / \Lambda \pm I T / T$ & $\Delta \Delta(T \Delta / \varsigma)$ & دانشكده ها \\
\hline & $v \varepsilon / \Lambda \pm 1 \cdot / v$ & $19(N / \Lambda)$ & معاونت غذا دارو \\
\hline \multirow[t]{4}{*}{$\mathrm{P}=. / 9 \& \wedge$} & & & وضعيت خدمت \\
\hline & $v e / q \pm 11 / r$ & $\operatorname{lr}(\Delta / \varphi)$ & مدير واحد \\
\hline & $V r / \wedge \pm 11 / r$ & $\operatorname{Tr}(I T / 9)$ & كارشناس مسئول \\
\hline & $V \leftarrow / \backslash \pm I T / V$ & $\operatorname{ler}(9 \varepsilon)$ & كارشناس \\
\hline \multirow[t]{5}{*}{$\mathrm{P}=\cdot / \Delta 9$} & & & سابقه كار \\
\hline & $v e / r \Delta \pm I r / v \Delta$ & $V(\Gamma r)$ & $\cdot-r$ \\
\hline & $v e / v \pm 1) / \wedge q$ & $r \cdot(1 r)$ & $\Delta-9$ \\
\hline & $\vee / / \wedge \pm|1 / 8|$ & $\operatorname{Rq}(Y T / \Lambda)$ & $1 \cdot-16$ \\
\hline & $V r / \wedge 1 \pm 11 / v V$ & $s \Delta(r \cdot / r)$ & ها سال به بالا \\
\hline
\end{tabular}

سكونت و شركت در كلاسهاى شادى و نشاط با وضعيت شادكامى

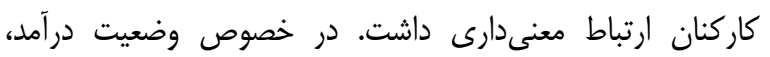
بر اساس نتايج مطالعه حاضر، اكثريت زنان شاغل در ستاد

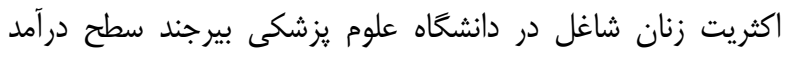
دانشگاه علوم يزشكى بيرجند از وضعيت نشاط متوسطى برخوردار

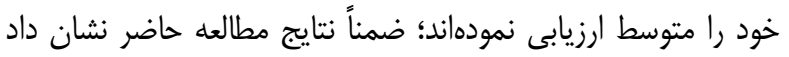

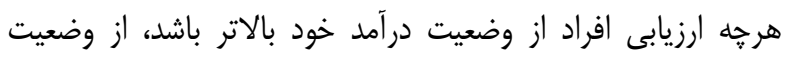
نشاط بهترى برخوردارند كه اين نتيجه مؤيد نتايج ساير مطالعات

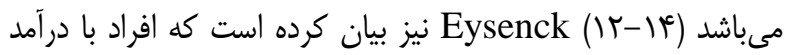

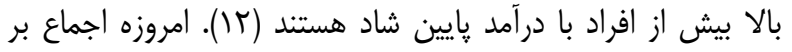

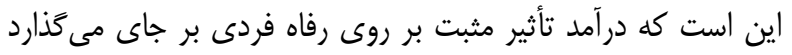

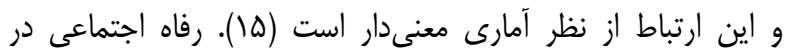
بودند. نتايج ساير مطالعات نيز مؤيد نتيجه مطالعه حاضر مى باشد

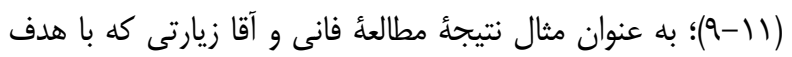
شناسايى مؤلفه هاى شادى فردى و سازمانى و سنجش وضعيت اين منان

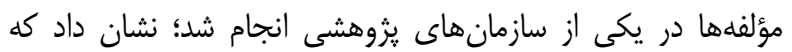

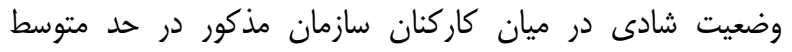
مىباشد (1). برخى روانشناسان، نشاط را نوعى هيجان مثبت مىدانند كه تاثير زرفى بر ساز وكارهاى جسمانى، شناختى و روانى روانى

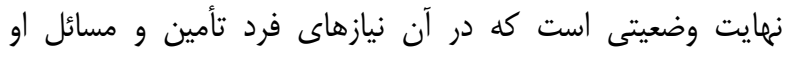

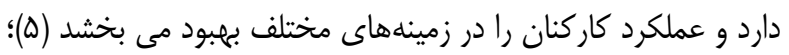
مديريت و مرتفع شده است و درنتيجه احساس شادكامى و خرسندى

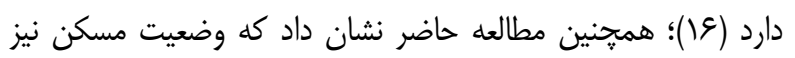

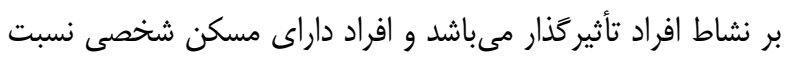

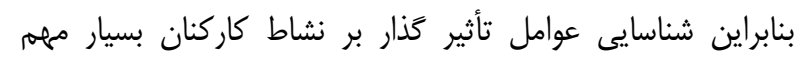

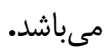
بر اساس نتايج مطالعه حاضر سه متغيّر سطح درآمد، محل 
نمونههاى مورد بررسى در مطالعه حاضر باشد.

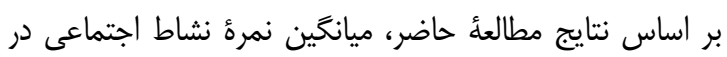
ميان زنان متأهل نسبت به زنان مجرد و مطلقه يا بيوه، بالاتر بود؛

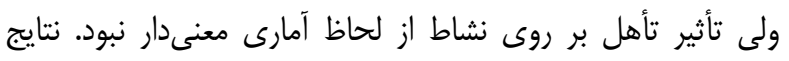

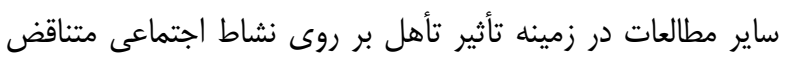

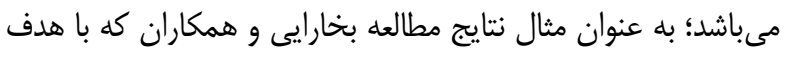
بررسى ميزان نشاط اجتماعى در شهر بوشهر و عوامل اجتماعى مؤثر بر آن انجام شد، نشان داد كه وضعيت تأهل بر نشاط اجتماعى تأثير

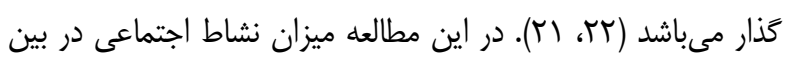

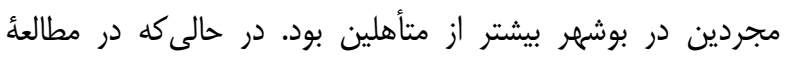

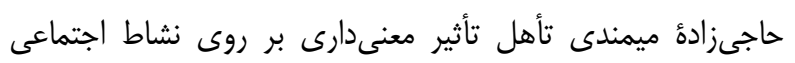
نداشت (r) (r).

مهمترين نقطه قوت اين مطالعه بررسى نشاط اجتماعى به

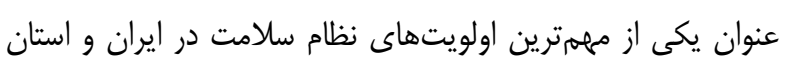

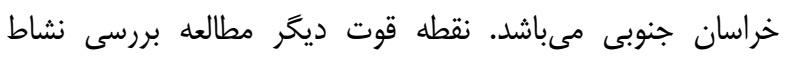
اجتماعى در زنان كارمند كه داراى تكثر نقشى مى باشند هست نقان. يكى از نقاط ضعف مطالعه، مقطعى بودن آن است كه در نتيجه،

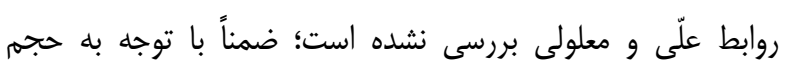
كارى بالاى كارمندان ممكن است افراد دقّت لازم در هنكام تكميل يرسشنامهها را نداشتند و نيزعدم معنىدارى برخى آناليزها، ممكن

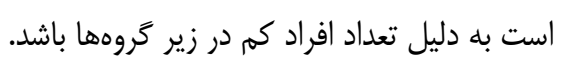

\section{نتيجه كيرى}

نتيجه مطالعه حاضر نشان داد كه وضعيت نشاط در سطح متوسط بوده است. با توجه به اينكه نشاط از شاخصههاى ارتقاى

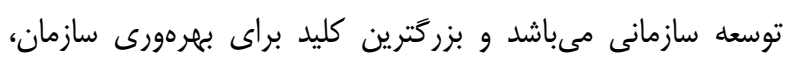

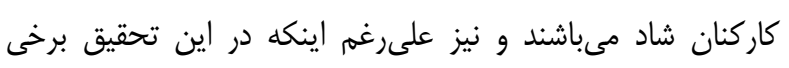

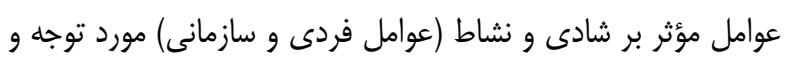

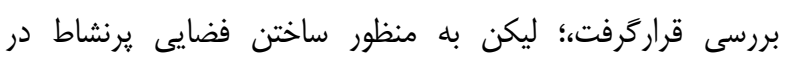

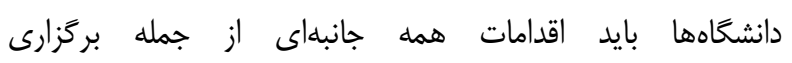

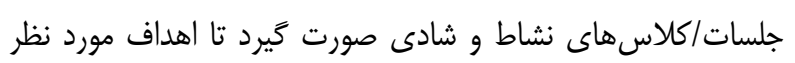
سريعتر محقق شوند.
به ساير افراد از نشاط بيشترى برخوردار هستند. ازآنجاكه وضعيت

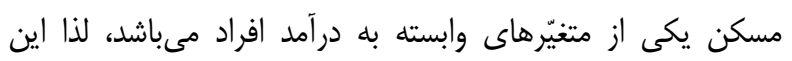
نتيجه منطقى بله نظر مىرسد.

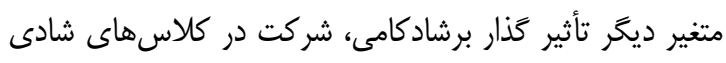

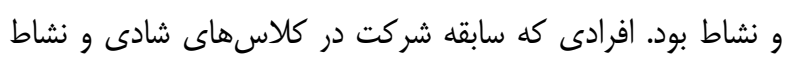
را داشتند از شادكامى بيشترى برخوردار بودند. نتايج ساير مطالعات

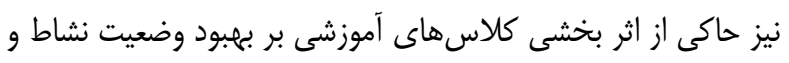

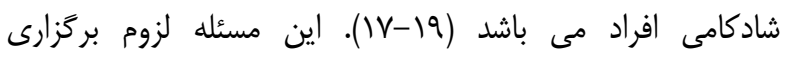
كلاسهاى شادى و نشاط كاركنان را در سازمانها ملموس مىنمايد. ساير متغيّرهاى فردى و سازمانى همجون سطح تحصيلات، وضعيت تأهل، محل خدمت و...بر شادكامى افراد مورد مطالعه

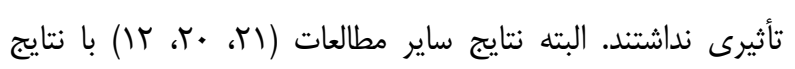
مطالعه حاضر همسو نمىباشد؛ به عنوان مثال نتايج مطالعه

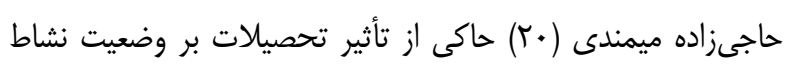

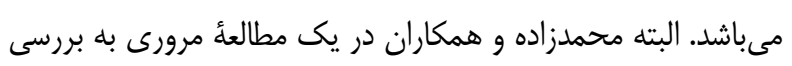

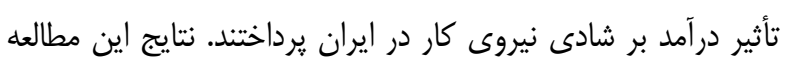
نشان داد كه ميزان تحصيلات تاثير آمارى معنىدارى بر ميزان

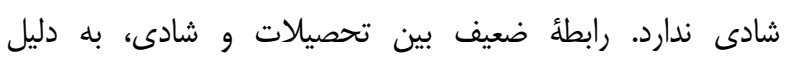

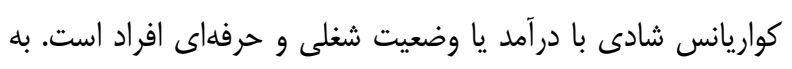

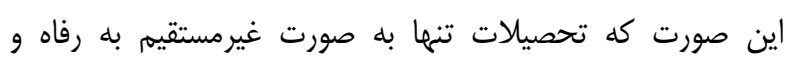

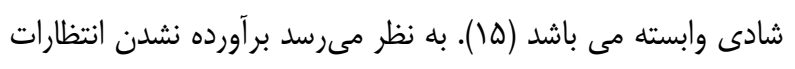

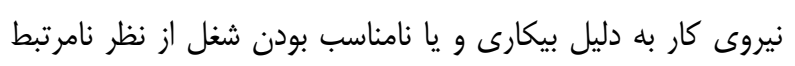

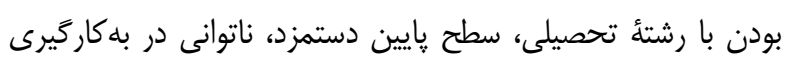

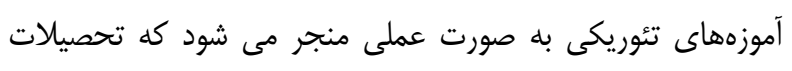
تأثير معنى دارى بر نشاط اجتماعى نداشته باشد.

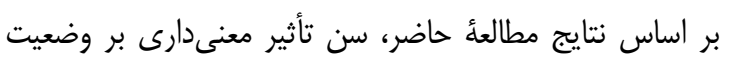

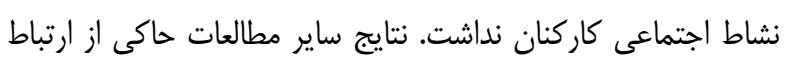

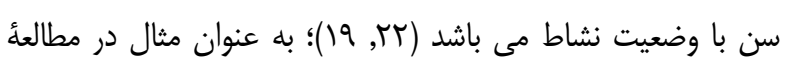

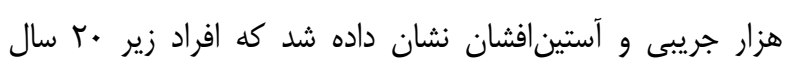
نسبت به كروههاى سنى بالاتر از وضعيت شادى مناسب ترى

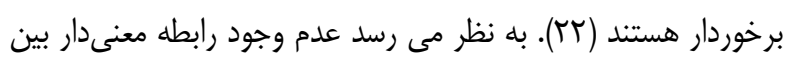

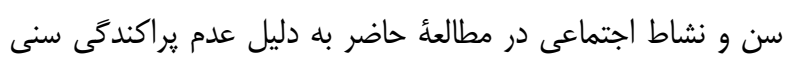




$$
\begin{aligned}
& \text { تضاد منافع } \\
& \text { نويسندَان مقاله اعلام مىدارند كه هيج كَنه تضاد منافعى در }
\end{aligned}
$$

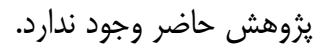

$$
\begin{aligned}
& \text { اين مقاله، حاصل طرح تحقيقاتى دانشجويى مصوب دانشكاه }
\end{aligned}
$$

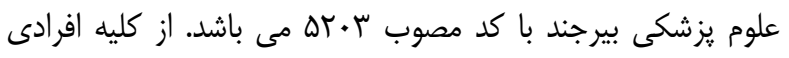

$$
\begin{aligned}
& \text { كه زمينه اجراى اين يثوهش را فراهم كردند، قدردانى مى گَردد. }
\end{aligned}
$$

\section{منابع:}

1- Afshani SA. An Investigation of Social Happiness among the Youth in the City of Yazd and the Factors Affecting It. Journal of Social analysis of social order and inequality. 2015; 7(2): 1-27. [Persian] Link

2- Hills P, Argyle M. Happiness, Introversion-Extroversion and Happy Introvets. Pers Individ Dif. 2001; 30 (4): 595608. DOI: 10.1016/S0191-8869(00)00058-1

3- Sharifzadeh Ha-S, Mirmohammad Tabar SA, Adlipour S. A Study of Factors Affecting Social Happiness in Iran: A Meta-analysis of Conducted Research. Strategy for Culture. 2018; 10(40): 159-80. [Persian] Link

4- Moeini B, Barati M, Farhadian M, Heydari ara M. The effectiveness of an educational intervention to enhance happiness in Iranian older people: Applying social support theory. Australas J Ageing. 2020; 39(1): e86-e93. DOI: 10.1111/ajag. 12702

5- Porsoltani ZarandiH, Shafiee SH. The relationship of Happiness at work with organizational entrepreneurship of employees of the Ministry of Sport and Youth. Journal of Human Resource Management in Sport. 2015; 2(2): 11728. [Persian] Link

6- Darvishi A, Kalateh S M. The Effect of Organizational Exhilaration on the Productivity of Employees in Sport and Youth General Office of Mazandaran Province. New Trends in Sport Management (NTSMJ). 2017; 5(16): 9-19. [Persian] Link

7- Moeini B, Babamiri M, Mohammadi Y, Barati M, Rashidi S.Relationship Between Happiness and Mental Health Status Among High School Female Students:A Descriptive Analytic Study. Nurs Midwifery J. 2017; 14(11): 94251. [Persian] Link

8- Tehrani A, Heidari H. The effect of group training based on Lazarus multimodal therapy on the happiness of women in Islamshahr, Iran. Journal of Fundamentals of Mental Health(JFMH). 2015; 17(2): 98-102. [Persian] DOI: 10.22038/JFMH.2015.4035

9- Zareshahabadi A, Torkan R, Hidari M. A Survey of the Relationship between Job Satisfaction and Social Happiness among High-schools Teachers of Giroft City. 2013; 23(4): 165-188. [Persian] Link

10- Akhshi N, Golabi F.Social happiness and social participation. Journal of Applied Sociology. 2015; 26(3): 139-60. [Persian] Link

11- Fani AA, Aghaziarati M. Identification of individual and organizational happiness Factors and assessment of this Factors. Organizational Culture Management. 2013; 11(1): 69-86. [Persian] DOI: 10.22059/jomc.2013.35318

12- Haghi S, Anbari M. A Study of Personal and Social Factors Impacting Women's Social Happiness Research Subjects: Women in Rural and Urban Areas of Delijan. Journal of Applied Sociology. 2014; 25(1): 1-26. [Persian] Link

13-Samiei Esfehani AR, Poordanesh S, Danesh H. The Social Factors Affecting the Social Happiness of Teachers (Case Study). Iranian Journal of Educational Society. 2018 ; 6(6): 186-200. [Persian] Link

14- Malekzadeh G, Rahnama N. Investigating factors affecting the vitality of the employees at work. Second International Conference on Management and Information and Communication Technology. 2016 Agu 7; Tehran; 2016. Link 
15- Mohamadzadeh P, Asgharpur H, Maniee O. The Effect of Income on Labor Force Happiness in Iran. Journal of Economic Research (Tahghighat- E- Eghtesadi). 2013; 48(1): 139-158. [Persian] DOI: 10.22059/jte.2013.30364.

16- Jafar Mikaeili MK, Fateme Sadat Homayoni. The Role of Socioeconomic Factors Affecting Happiness. A Research Journal on Social Work. 2017; 4(12): 1-41. [Persian] DOI: 10.22054/RJSW.2017.10035

17- Paivastegar M, Mousavi SA. The Effects of self-regulation Skills on Happiness, Learning Strategies and Motivation believes of Students. Strategic Studies on Youth ans Sports. 2014; 13(23): 47-62. [Persian] Link

18- Ghasemi A, Abedi A, Baghban I. The impact of group education based on snyder's hop theory on the rate of happiness in eldery's life. Knowledge \& Research in Applied Psychology. 2009; 11(41): 17-40. [Persian] Link

19- Aghadavood S R. Studying the Effects of Employees Happiness Management System on Employees' Performance Based On Steers' Model (Case: Isfahan Branch Gas Company). Human Resource Management in Oil Industry. 2018; 9(35): 33-58. [Persian] Link

20- Hajizade Mimandi M, Torkan R. A study of the Level of and factors related to Social Happiness (Case study: Yazd university students). Urban Sociological Studies, 2015; 5(16): 59-86. [Persian] Link

21- Bokharaei A, Sharbatein MH, Tavafi P. A Sociological Study of the Relationship between Happiness and Social Health: (A Case Study of the 18-30-Year-Old Youths of the City of Malayer). Social Development \& Welfare Planning. 2016; 7(25): 1-39. [Persian] DOI: 10.22054/QJSD.2016.3851

22- Hezarjaribi J, Astinfeshan, P. Review of Influential Factors in Social Bliss (Emphasis on Tehran Province). Journal of Applied Sociology. 2009; 20(1): 119-146. [Persian] Link 